\title{
Effects of Fruit Extract Drink on Alcohol Metabolic Enzymes in Ethanol-treated Rats
}

\author{
Sung-Su Kim ${ }^{\dagger}$ \\ Department of Biomedical Laboratory Science, Daejeon University, Daejeon 300-716, Korea
}

\begin{abstract}
Alcoholism is a significant global health problem. Alcohol dehydrogenase and aldehyde dehydrogenase play important roles in the metabolism of alcohol and aldehyde. In this study, we aimed to investigate the eliminatory effects of a fruit extract drink on alcohol metabolism in drunken Sprague-Dawley (SD) rats. Male SD rats were given a fruit extract drink or a commercial product $(10 \mathrm{~mL} / \mathrm{kg}) 30 \mathrm{~min}$ prior to $40 \%(5 \mathrm{~g} / \mathrm{kg})$ ethanol ingestion. To assay the effect of the fruit extract drink on blood ethanol concentration, blood samples were taken from the saphenous vein at 3 and $5 \mathrm{~h}$ after ethanol ingestion. The blood concentrations of alcohol, alcohol dehydrogenase, and aldehyde dehydrogenase were significantly lower in the fruit extract drink group than in the control group, in a time-dependent manner. However, the alanine aminotransferase and aspartate aminotransferase activities of all experimental groups were unaltered compared to those of the control group. These results suggested that fruit extract drink intake can have a positive effect on the reduction of alcohol, alcohol dehydrogenase, and aldehyde dehydrogenase concentrations in the blood and may alleviate acute ethanol-induced hepatotoxicity by altering alcohol metabolic enzyme activities.
\end{abstract}

Key Words: Alcoholism, Fruit extract, Alcohol dehydrogenase, Aldehyde dehydrogenase, Liver injury

\section{INTRODUCTION}

Alcohol is the most commonly used and abused drug. Alcohol overconsumption is the main cause of liver disease worldwide and alcoholic liver disease is ranked among the major causes of morbidity and mortality in the world (Smathers et al., 2011), and it affects millions of people each year.

Alcohol is a mild toxicant and its toxicity primarily depends upon its metabolism. The liver is the first and primary target organ for alcohol metabolism (Lieber, 1988). Other organs, including the kidneys, brain, and lungs, may

*Received: May 24, 2014 / Revised: August 7, 2014

Accepted: August 7, 2014

${ }^{\dagger}$ Corresponding author: Sung-Su Kim. Department of Biomedical Laboratory Science, Daejeon University, Daejeon 300-716, Korea.

Tel: +82-42-280-2903, Fax: +82-42-280-2904

e-mail: sungsu@dju.kr

○The Korean Society for Biomedical Laboratory Sciences. All rights reserved. also be affected by alcohol toxicity (Guidot and Roman, 2002).

The persimmon (Diospyros kaki) is a fruit that is eaten fresh, and the leaves of this tree can be infused in water to make a popular tea. Persimmon extract is known to have anti-oxidant and hypolipidemic effects (Jung et al., 2004; Kim et al., 2001). However, the protective effect of extracts of persimmon or other fruits against liver damage resulting from acute alcohol-induced hepatotoxicity remain unclear.

The aim of the current study was to investigate the protective effects of fruit extracts on alcohol-induced hepatotoxicity in rats. To determine intake of fruit extract caused any liver damage, serum levels of alanine aminotransferase (ALT) and aspartate aminotransferase (AST) were also determined. Serum alcohol dehydrogenase (ADH) activity and aldehyde dehydrogenase (ALDH) activities in the liver were also determined to evaluate the protective effects of fruit extracts on ethanol-induced hepatotoxicity. 


\section{MATERIALS AND METHODS}

\section{Preparation of fruit extract}

All fruit used for preparing fruit extract were obtained from Tae Young F\&I (Daejeon, Korea). Fresh apple, pear, and sweet persimmon fruits were washed and ground with grinder to perform successive extractions. One kilogram of fresh fruit was incubated in $5 \mathrm{~L}$ of distilled water at $90^{\circ} \mathrm{C}$ for $3 \mathrm{~h}$, and filtered using a 5- $\mu \mathrm{m}$ filter. The filtrate was heated and dried to over $60 \%$ concentration using a rotary vacuum evaporator.

\section{Animals}

Male SD rats (180 200 g, 6 weeks old) were used for the study. After 1 week of adaptation, all animals were housed in a temperature- $\left(25^{\circ} \mathrm{C}\right)$ and humidity- $(50 \%)$ controlled room with a 12-h light/12-h dark cycle. Water and a normal standard pellet diet were available ad libitum throughout the experimental period.

\section{Acute ethanol-induced liver injury in mice}

After 1 week of acclimatization, the rats were randomly allocated into 3 groups. The three groups were Group I (control group): rats received $0.2 \mathrm{~mL}$ water by gavage, Group II (CS-treated group): the rats were pre-treated with Call Sign $^{\circledR}$, a commercial product, at a dose of $1 \mathrm{~mL} / \mathrm{kg}$, and Group III (Mir-TY-treated group): the rats were pretreated with fruit extract $(1 \mathrm{~mL} / \mathrm{kg})$.

After $30 \mathrm{~min}$, each rat received ethanol diluted in water $(40 \%, \mathrm{v} / \mathrm{v})$ at $5 \mathrm{~g} / \mathrm{kg}$. At 3 and $5 \mathrm{~h}$ after the administration of ethanol, blood was collected from the saphenous vein to determine biochemical parameters. The rats received humane care, and experiments were performed according to the criteria outlined in the Guide for the Care and Use of Laboratory Animals and with approval of the Animal Care and Use Committee of Daejeon University (DJUARB2013005).

\section{Serum ethanol concentration}

An ethanol assay kit (Abcam, USA) was used, following a slightly modified version of the manufacturer's protocol, to determine the serum ethanol concentration. Briefly, $5 \mu \mathrm{l}$ of serum was mixed with $50 \mu \mathrm{l}$ of reaction mixture. After mixing for $30 \mathrm{~min}$ at $37^{\circ} \mathrm{C}$ the absorbance was measured at a wavelength of $570 \mathrm{~nm}$. The ethanol concentration was calculated according to the equation provided with the kit.

\section{Assessment of AST and ALT}

AST and ALT activities are commonly used to assess hepatic function. Serum levels of AST and ALT were assessed using an AST or an ALT Kit (Abcam, USA). Serum was diluted with phosphate buffered saline (PBS) prior to performing the assay. Yellow-colored hydrazones, which are metabolites of AST and ALT, were measured at a wavelength of $570 \mathrm{~nm}$.

\section{Assessment of ADH and ALDH}

The reaction mixtures for assay were pre-incubated with $50 \mu$ of enzyme source for $5 \mathrm{~min}$ at room temperature and the change in absorbance at $450 \mathrm{~nm}$ was monitored for 30 min to determine the amount of NADH generated. The activity was calculated relative to a sample blank.

\section{Statistical analysis}

All data are expressed as mean \pm standard deviation. Statistical analyses were performed using the software SPSS. The Student's $t$-test was used to determine the significance of differences among groups; differences were considered to be significant when $P<0.05$.

\section{RESULTS}

\section{Determination of ethanol concentration in serum}

Serum alcohol concentrations of fruit extract-treated rats were measured at 3 and $5 \mathrm{~h}$ after administration of $40 \%$ ethanol. After ethanol exposure, serum alcohol concentrations ranged from 2.20 to $2.57 \mathrm{nmol} / \mu \mathrm{L}$ at $5 \mathrm{~h}$ (Fig. 1). Serum alcohol concentrations were also significantly lower in groups administered CS $(2.57 \pm 0.05 \mathrm{nmol} / \mu \mathrm{L})$ than in group I at $5 \mathrm{~h}$. At $5 \mathrm{~h}$, the serum alcohol concentration of the experimental group treated with Mir-TY $(2.20 \pm 0.10$ $\mathrm{nmol} / \mu \mathrm{L}$ ) was approximately 3 -fold lower than that of the negative control group, which was administered ethanol 


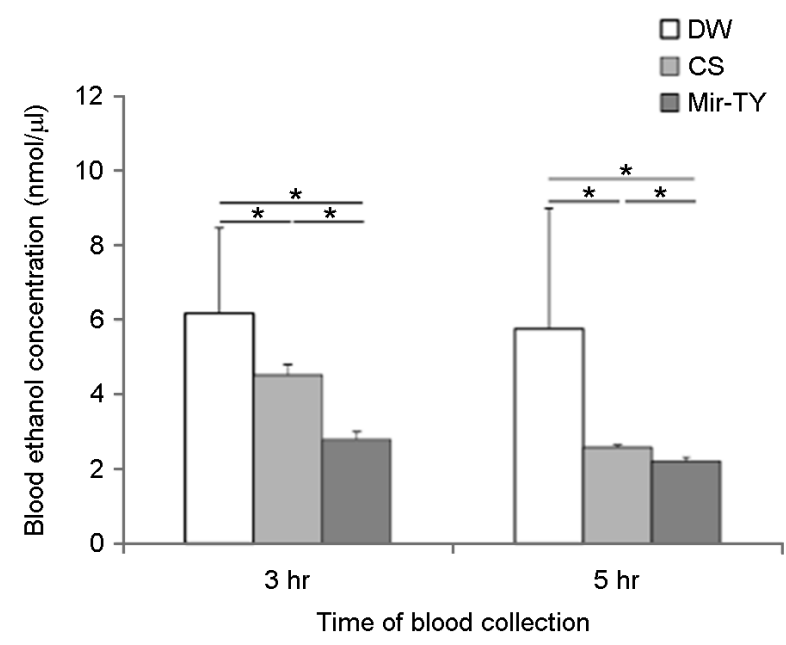

Fig. 1. Effects of fruit extract drinks on blood ethanol levels in drunken rats. Values are shown at the mean \pm S.D. for 10 rats. Asterisks indicate significant differences between groups $\left({ }^{*} P<0.05\right)$.

alone $(5.65 \pm 4.18 \mathrm{nmol} / \mu \mathrm{L})$. Serum alcohol concentrations of the groups administered CS or Mir-TY decreased in a time-dependent manner. The lowest serum alcohol concentration was observed in the group treated with Mir-TY.

\section{Effects of fruit extract drink on serum ALT and AST activity levels}

Ethanol-induced liver injury is indicated by elevated serum ALT and AST activity levels. However, some fruit extract drinks can also cause liver damage, which would be indicated by increases in serum AST or ALT, and AST or ALT is increases in the serum, which were slightly but increased compared with those of the negative control group. In this study, we aimed to determine whether the fruit extract drink would cause injury to rat livers. The fruit extract drink did not produce any signs or symptoms of toxicity, and no mortality was recorded during the study. Pre-treatment with $\mathrm{CS}$ and Mir-TY at $30 \mathrm{~min}$ before ethanol exposure did not increase levels of ALT (Fig. 2A) or AST (Fig. 2B), and resulted in significant protection of the liver.

\section{Effects of fruit extract drink on ADH and ALDH levels}

At $3 \mathrm{~h}$, serum ADH concentrations were also slightly higher in groups treated with CS than in the negative control group. However, at $5 \mathrm{~h}$, the ADH concentration was lower
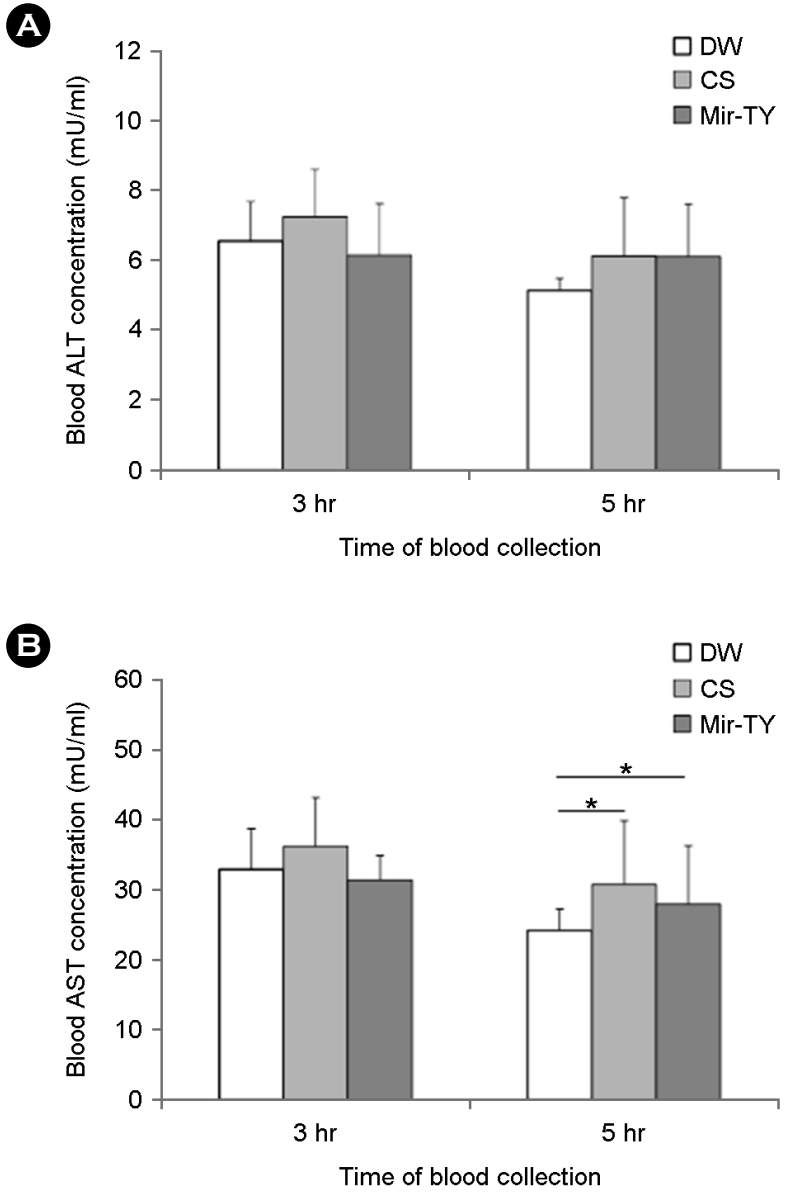

Fig. 2. Effects of fruit extract drinks on serum of alanine aminotransferase (ALT) and aspartate aminotransferase (AST) activities in drunken rats. Values are shown as the mean \pm S.D. for 10 rats. Asterisks indicate significant differences between groups $(* P<0.05)$.

in the groups treated with CS $(2.55 \pm 1.97 \mathrm{nmol} / \mu \mathrm{L})$ than in the negative control group. In the Mir-TY treated group, the $\mathrm{ADH}$ concentration $(1.27 \pm 0.06 \mathrm{mU} / \mathrm{mL})$ at $3 \mathrm{~h}$ was approximately 4-fold lower than that of the negative control group, which was treated with ethanol alone $(5.00 \pm 1.70$ $\mathrm{mU} / \mathrm{mL}$ ). The lowest serum ADH concentration was observed in the group treated with Mir-TY at $5 \mathrm{~h}$ (Fig. 3A). At $3 \mathrm{~h}$, the serum ALDH concentration of the CS-treated group had doubled, but that of the Mir-TY treated group decreased in a time-dependent manner (Fig. 3B).

\section{DISCUSSION}

Ethanol dependence and ethanol abuse are known to be 
primary causes of end-stage liver disease and substantial morbidity and mortality (Schuckit, 2009). Alcoholic liver injury is a major complication of excessive ethanol intake that results in serious health damage to individuals and is a significant drain on social healthcare resources.

A

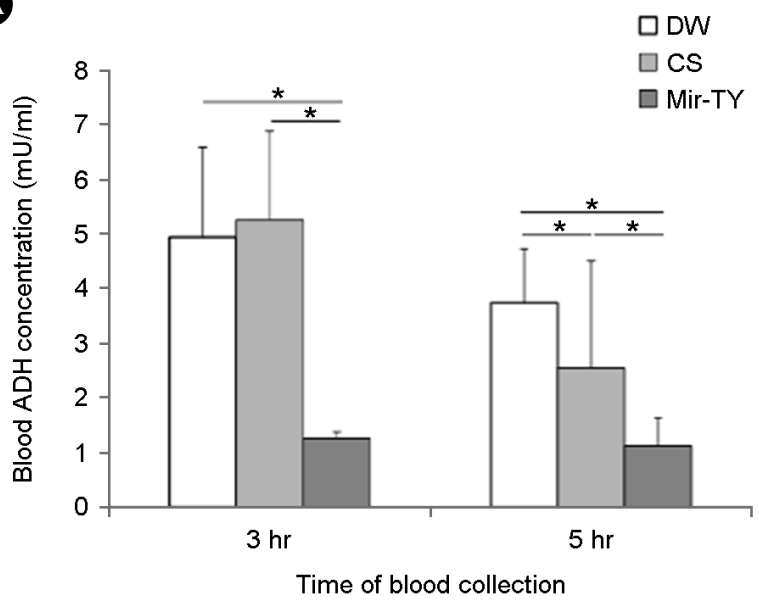

B

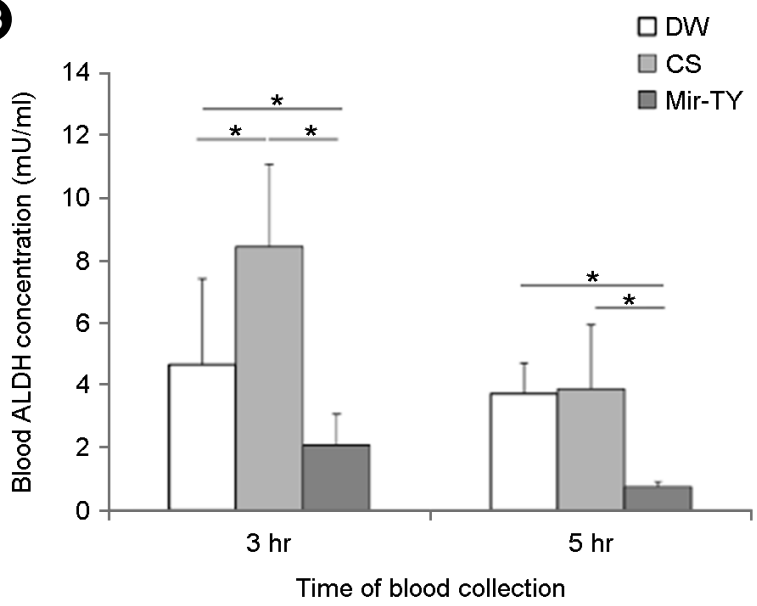

Fig. 3. Effects of fruit extract drinks on alcohol dehydrogenase (ADH) and aldehyde dehydrogenase (ALDH) activities in drunken rats. Values are shown as the mean \pm S.D. for 10 rats. Asterisks indicate significant differences between groups $\left({ }^{*} P<0.05\right)$.
In this study, consumption of a fruit extract was demonstrated to significantly improve serum biochemical indices and to influence ethanol metabolizing enzymes. Ethanol consumption is notably associated with hepatic damage and a prominent sign of hepatic injury is the leakage of cellular enzymes (AST, ALT) into the serum (Sehrawat and Sultana, 2006). Ethanol-treated rats show high activity of these toxicity marker enzymes, indicating increased membrane permeability, cellular damage, and/or necrosis of hepatocytes (Baldi et al., 1993; Tahir and Sultana, 2011).

Acute ethanol intake causes significant increases in serum levels of AST and ALT. Compared to the ethanol-treated group, treatment with CS and Mir-TY did not alter serum ALT (Fig. 2A) and AST activity (Fig. 2B) in the present study. Mir-TY did not appear to cause liver injury and shows the potential for use as a health drink.

Ethanol is primarily catalyzed into acetaldehyde by alcoholic dehydrogenase (ADH) and cytochrome P4502E1, key enzymes in the microsomal ethanol oxidizing system. Subsequently, acetaldehyde is transformed into acetic acid by mitochondrial and cytosolic acetaldehyde dehydrogenase (ALDH) isoenzymes (Klyosov et al., 1996). Silymarin (Song et al., 2006), a root extract of Decalepis hamiltonii (Srivastava, 2006), and glycoproteins from Acanthopanax senticosus (Choi et al., 2006) have also been shown to have protective effects against ethanol-induced hepatotoxicity in mice and rats.

In an acute ethanol treatment model, Mir-TY administration significantly attenuated ethanol-induced damage in rat livers. These results suggest that Mir-TY can be used as a health drink for reducing hepatotoxicity.

\section{Acknowledgements}

This work was supported by the RIC program of Ministry of Knowledge Economy in Daejeon University.

Table 1. Summary of chemical analyses of the effect of fruit extract drink on ethanol-treated rats

\begin{tabular}{|c|c|c|c|c|c|c|c|c|c|c|}
\hline & \multicolumn{2}{|c|}{ Ethanol in serum } & \multicolumn{2}{|c|}{ AST } & \multicolumn{2}{|c|}{ ALT } & \multicolumn{2}{|c|}{$\mathrm{ADH}$} & \multicolumn{2}{|c|}{ ALDH } \\
\hline & $3 \mathrm{~h}$ & $5 \mathrm{~h}$ & $3 \mathrm{~h}$ & $5 \mathrm{~h}$ & $3 \mathrm{~h}$ & $5 \mathrm{~h}$ & $3 \mathrm{~h}$ & $5 \mathrm{~h}$ & $3 \mathrm{~h}$ & $5 \mathrm{~h}$ \\
\hline $\mathrm{CS}$ & $\downarrow$ & $\downarrow \downarrow$ & - & - & - & - & - & $\downarrow \downarrow$ & $\uparrow$ & $\downarrow$ \\
\hline Mir-TY & $\downarrow \downarrow$ & $\downarrow \downarrow$ & - & - & - & - & $\downarrow$ & $\downarrow \downarrow$ & - & $\downarrow \downarrow$ \\
\hline
\end{tabular}




\section{REFERENCES}

Baldi E, Burra P, Plebani M, Salvagnini M. Serum malondialdehyde and mitochondrial aspartate aminotransferase activity as markers of chronic alcohol intake and alcoholic liver disease. Ital J Gastroenterol. 1993. 25: 429-432.

Choi JS, Yoon TJ, Kang KR, Lee KH, Kim WH, Suh YH, Song J, Jung MH. Glycoprotein isolated from Acanthopanax senticosus protects against hepatotoxicity induced by acute and chronic alcohol treatment. Biol Pharm Bull. 2006. 29: 306-314.

Guidot DM, Roman J. Chronic ethanol ingestion increases susceptibility to acute lung injury: role of oxidative stress and tissue remodeling. Chest. 2002. 122: 309S-314S

Jung KM, Kang GH, Kwon MK, Song IK, Cho DH, Chou YD. Chemical components and antioxidant activity of persimmon leaves. Kor J Food Preservation. 2004. 11: 175-181.

Kim SK, Lee HY, Kim MK. Effect of water and ethanol extracts of persimmon leaf and green tea different conditions on lipid metabolism and antioxidant capacity in 12-month old rats. Kor J Nutr. 2001. 34: 499-512.

Klyosov AA, Rashkovetsky LG, Tahir MK, Keung WM. Possible role of liver cytosolic and mitochondrial aldehyde dehydro- genases in acetaldehyde metabolism. Biochemistry. 1996. 35: 4445-4456.

Lieber CS. Biochemical and molecular basis of alcohol-induced injury to liver and other tissues. N Engl J Med. 1988. 319: 1639-1650.

Schuckit MA. Alcohol-use disorders. Lancet. 2009. 373: 492-501. Sehrawat A, Sultana S. Evaluation of possible mechanisms of protective role of Tamarix gallica against DEN initiated and 2-AAF promoted hepatocarcinogenesis in male Wistar rats. Life Sci. 2006. 79: 1456-1465.

Smathers RL, Galligan JJ, Stewart BJ, Petersen DR. Overview of lipid peroxidation products and hepatic protein modification in alcoholic liver disease. Chem Biol Interact. 2011. 192: 107 -112 .

Song Z, Deaciuc I, Song M, Lee DY, Liu Y, Ji X, McClain C. Silymarin protects against acute ethanol-induced hepatotoxicity in mice. Alcohol Clin Exp Res. 2006. 30: 407-413.

Srivastava A, Shivanandappa T. Hepatoprotective effect of the aqueous extract of the roots of Decalepis hamiltonii against ethanol-induced oxidative stress in rats. Hepatol Res. 2006. 35: 267-275

Tahir M, Sultana S. Chrysin modulates ethanol metabolism in Wistar rats: a promising role against organ toxicities. Alcohol Alcohol. 2011. 46: 383-392. 